\title{
Antiarrhythmic and electrophysiological effects of GYKI-16638, a novel $N$-(phenoxyalkyl) $-N$-phenylalkylamine, in rabbits
}

\author{
István Baczkó a , Nasruddin E. El-Reyani ${ }^{\text {a }}$, András Farkas a ${ }^{\text {a }}$ László Virág a , Norbert Iost ${ }^{\text {a }}$, \\ István Leprán ${ }^{\mathrm{a}, *}$, Péter Mátyus ${ }^{\mathrm{b}}$, András Varró a , Julius Gy. Papp ${ }^{\mathrm{a}}$ \\ a Department of Pharmacology and Pharmacotherapy, Faculty of Medicine, University of Szeged and Research Unit of the Hungarian Academy of \\ Sciences, Dóm tér 12, P.O. Box 427, H-6701 Szeged, Hungary \\ ${ }^{\mathrm{b}}$ Institute of Organic Chemistry, Semmelweis University of Medicine, Högyes u. 7., H-1092 Budapest, Hungary
}

Received 13 June 2000; received in revised form 31 July 2000; accepted 4 August 2000

\begin{abstract}
The effect of $N$-[4-[2- $N$-methyl- $N$-[1-methyl-2-(2,6-dimethylphenoxy)ethylamino]-ethyl]-phenyl]-methanesulfonamide.hydrochloride (GYKI-16638; 0.03 and $0.1 \mathrm{mg} / \mathrm{kg}$, i.v.), a novel antiarrhythmic compound, was assessed and compared to that of D-sotalol (1 and 3 $\mathrm{mg} / \mathrm{kg}$, i.v.) on arrhythmias induced by $10 \mathrm{~min}$ of coronary artery occlusion and $10 \mathrm{~min}$ of reperfusion in anaesthetized rabbits. Also, its cellular electrophysiological effects were studied in rabbit right ventricular papillary muscle preparations and in rabbit single isolated ventricular myocytes. In anaesthetized rabbits, intravenous administration of 0.03 and $0.1 \mathrm{mg} / \mathrm{kg}$ GYKI-16638 and 1 and $3 \mathrm{mg} / \mathrm{kg}$ D-sotalol significantly increased survival during reperfusion (GYKI-16638: $82 \%$ and 77\%, D-sotalol: $75 \%$ and $83 \%$ vs. 18\% in controls, $P<0.05$, respectively). GYKI-16638 $(0.1 \mathrm{mg} / \mathrm{kg})$ significantly increased the number of animals that did not develop arrhythmias during reperfusion $(46 \%$ vs. $0 \%$ in controls, $P<0.05$ ). In isolated rabbit right ventricular papillary muscle, $2 \mu \mathrm{M} \mathrm{GYKI}-16638$, at $1 \mathrm{~Hz}$ stimulation frequency, lengthened the action potential duration at $50 \%$ and $90 \%$ repolarization $\left(\mathrm{APD}_{50-90}\right)$ without influencing the resting membrane potential and action potential amplitude (APA). It decreased the maximal rate of depolarization $\left(V_{\max }\right)$ in a use-dependent manner. This effect was statistically significant only at stimulation cycle lengths shorter than $700 \mathrm{~ms}$. The offset kinetics of this $V_{\max }$ block were relatively rapid, the corresponding time constant for recovery of $V_{\max }$ was $328.2 \pm 65.0 \mathrm{~ms}$. In patch-clamp experiments, performed in rabbit ventricular myocytes, $2 \mu \mathrm{M}$ GYKI-16638 markedly depressed the rapid component of the delayed rectifier outward and moderately decreased the inward rectifier $\mathrm{K}^{+}$current without significantly altering the slow component of the delayed rectifier and transient outward $\mathrm{K}^{+}$currents. These results suggest that in rabbits, GYKI-16638 has an in vivo antiarrhythmic effect, comparable to that of D-sotalol, which can be best explained by its combined Class I/B and Class III actions. C 2000 Elsevier Science B.V. All rights reserved.
\end{abstract}

Keywords: Antiarrhythmic drug; Reperfusion arrhythmia; Action potential duration; $V_{\max }$

\section{Introduction}

The analysis of the Cardiac Arrhythmia Suppression Trials (CAST-I and CAST-II) prompted the reconsideration of prophylactic antiarrhythmic treatment after myocardial infarction. The results shed light on the controversy that Class I/C type $\mathrm{Na}^{+}$channel blockers, i.e. flecainide and encainide, increased mortality in survivors of myocardial infarction despite their ability to reduce the number of

\footnotetext{
" Corresponding author. Tel.: +36-62-545-676; fax: +36-62-544-565

E-mail address: lepran@phcol.szote.u-szeged.hu (I. Leprán).
}

premature ventricular beats (The Cardiac Arrhythmia Suppression Trial (CAST) Investigators, 1989; The Cardiac Arrhythmia Suppression Trial II Investigators, 1992). The results of these trials and those of the ESVEM and CASCADE trials shifted the attention to cardiac $\mathrm{K}^{+}$channel blockers (Mason, 1993; The CASCADE Investigators, 1993).

As a disappointment, in the SWORD trial D-sotalol, a so-called 'pure' Class III antiarrhythmic drug, which is known to block cardiac $\mathrm{K}^{+}$channels selectively, was shown to increase mortality in subsets of patients with myocardial infarction and lowered ejection fraction (Waldo et al., 1996). 


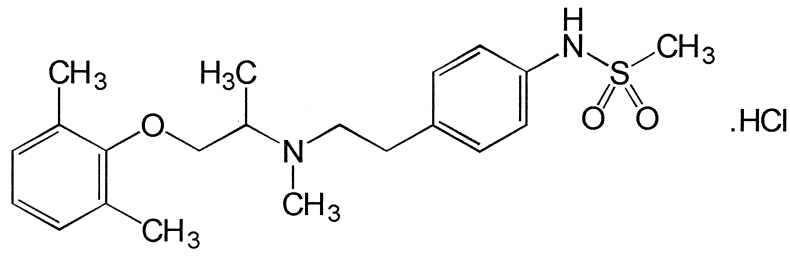

Fig. 1. Chemical structure of GYKI-16638.

Accordingly, special attention has been paid to antiarrhythmic drugs with complex effects on different ion channels and receptors. These include D,L-sotalol (a delayed rectifier $\mathrm{K}^{+}$channel blocker and $\beta$-adrenoceptor antagonist) and amiodarone (a $\mathrm{K}^{+}$channel blocker possessing $\mathrm{Na}^{+}$and $\mathrm{Ca}^{2+}$ channel blocking properties and antiadrenergic activity). Amiodarone has been shown to exert a strong antiarrhythmic effect in a number of studies and is currently considered to be one of the most efficacous antiarrhythmic drugs available in clinical practice. Long-term treatment with amiodarone, however, leads to the development of serious extracardiac side effects (Hilleman et al., 1998). Therefore, it seems worthwhile to pursue the development of novel amiodarone-like compounds with marked antiarrhythmic potency but without unwanted extracardiac side effects.

$N$-[4-[2- $N$-methyl- $N$-[1-methyl-2-(2,6-dimethylphenoxy) ethylamino] - ethyl] - phenyl] - methanesulfonamide. hydro chloride (GYKI-16638; Fig. 1) is a novel $N$-(phenoxyalkyl)- $N$-phenylalkylamine that has been developed recently. Although it is not an amiodarone congener, based on its chemical structure, the compound is expected to show amiodarone-like electrophysiological effects, i.e. both Class I/B and Class III properties.

In the present study, we investigated the effect of GYKI-16638 and D-sotalol on the incidence of coronary artery occlusion and reperfusion-induced arrhythmias in anaesthetized rabbits. We also studied the cellular electrophysiological effects of GYKI-16638 in rabbit right ventricular papillary muscle and in rabbit single isolated ventricular myocytes.

\section{Materials and methods}

\subsection{Animals}

Male rabbits weighing 2-3 kg were used for the experiments. The animals were allowed to have tap water and laboratory rabbit chow (Altromin, Gödöllő, Hungary) ad libitum until the experiment. The animal handling protocol was reviewed and approved by the Ethics Committee for the Protection of Animals in Research of the Faculty of Medicine, University of Szeged, Szeged, Hungary.

\subsection{Coronary artery ligation and reperfusion}

The animals were anaesthetized with $30 \mathrm{mg} / \mathrm{kg}$ pentobarbitone-Na given intravenously in a volume of $1 \mathrm{ml} / \mathrm{kg}$ into the marginal vein of the right ear. Acute coronary artery occlusion and reperfusion were performed as described by Coker (1989). To measure blood pressure, a catheter filled with isotonic saline containing $500 \mathrm{IU} / \mathrm{ml}$ heparin (the animals were not heparinized) was introduced into the right carotid artery. The catheter was connected to a pressure transducer (Gould-Statham, P23ID, Hugo Sachs Electronik, March-Hugstetten, Germany) and blood pressure was recorded on an oscillographic recorder (Watanabe, WTR 331, Hugo Sachs Electronik). For the infusion of drugs, another catheter was introduced into the marginal vein of the left ear.

After tracheal cannulation, thoracotomy was performed in the fourth intercostal space and artificial ventilation was started with room air (Harvard rodent ventilator, model 683, Harvard Apparatus, South Natick, MA, USA), with respiratory volume and rate subsequently adjusted to keep blood gases and $\mathrm{pH}$ within the normal range $(7 \mathrm{ml} / \mathrm{kg}$ / stroke, 40 strokes/min, respectively). Following pericardiotomy, a loose loop of 4-0 atraumatic silk (Ethicon, Edinburgh, UK) was placed around the first branch of the left circumflex coronary artery just under its origin. Both ends of the ligature were led out of the thoracic cavity through a flexible tube.

After stabilization of blood pressure and heart rate (approximately $10 \mathrm{~min}$ ), saline or 0.03 or $0.1 \mathrm{mg} / \mathrm{kg}$ GYKI-16638 or 1 or $3 \mathrm{mg} / \mathrm{kg}$ D-sotalol was administered i.v. during a 1-min infusion in a volume of $2 \mathrm{ml} / \mathrm{kg}, 5 \mathrm{~min}$ prior to coronary artery occlusion.

Coronary artery occlusion and, thus, local myocardial ischaemia, was produced by tightening the loose loop and clamping on the silk. After $10 \mathrm{~min}$ of coronary artery occlusion, the ligature was released to permit reperfusion for $10 \mathrm{~min}$.

The electrocardiogram (lead I, II, III) was registered using a thermographic recorder (ESC $1104 \mathrm{CH}$, Multiline, Esztergom, Hungary) with subcutaneous needle electrodes. QT interval was defined as the time between the first deviation from the isoelectric line during the PR interval until the end of the TU wave. QT interval corrected for heart rate $\left(\mathrm{QT}_{\mathrm{c}}\right)$ was calculated using the following equation of Carlsson et al. (1993a): $\mathrm{QT}_{\mathrm{c}}=\mathrm{QT}-0.175 \times(\mathrm{RR}$ -300 ).

Arrhythmias were detected and diagnosed in accordance with the Lambeth conventions as ventricular tachycardia, ventricular fibrillation and other types of arrhythmias, including single extrasystoles, bigeminy, salvos and bradycardia (Walker et al., 1988).

At the end of the experiment, heparin-Na $(500 \mathrm{IU} / \mathrm{kg}$, i.v.) was administered and the animals were killed. The hearts were cut out from the chest in order to determine the size of the occluded zone. After the ligation was 
tightened, the hearts were retrogradely perfused via the aorta with $20 \mathrm{ml}$ saline and $10 \mathrm{ml}$ of $96 \%$ ethanol as previously described by Leprán et al. (1983). The non-denaturated area (occluded zone) was excised and its extent is expressed as a percentage of the total wet weight of the ventricles. Four animals with an occluded zone less than $16 \%$ or larger than $32 \%$ were excluded from the final evaluation.

\subsection{Drug administration protocol}

D-Sotalol (1 or $3 \mathrm{mg} / \mathrm{kg}$ ) was dissolved in saline, and GYKI-16638 (0.03 or $0.1 \mathrm{mg} / \mathrm{kg}$ ) was dissolved in propylene glycol/saline, 1:1 mixture. Both drugs were applied 5 min prior to coronary artery ligation in a volume of 2 $\mathrm{ml} / \mathrm{kg}$. Each dose was prepared on the day of the experiment. Control animals received propylene glycol/saline, $1: 1$ mixture in a volume of $2 \mathrm{ml} / \mathrm{kg}$.

\subsection{Measurement of action potential parameters in rabbit right ventricular papillary muscle}

Following cervical dislocation, the heart of each animal was rapidly removed through a right lateral thoracotomy. The hearts were immediately rinsed in oxygenated Tyrode's solution containing (in $\mathrm{mM}$ ): $\mathrm{NaCl}, 115 ; \mathrm{KCl}, 4 ; \mathrm{CaCl}_{2}$, 1.2; $\mathrm{MgCl}_{2}, 1 ; \mathrm{NaHCO}_{3}, 21.4$; and glucose, 11. The $\mathrm{pH}$ of this solution was 7.35-7.45 when gassed with $95 \% \mathrm{O}_{2}$ and $5 \% \mathrm{CO}_{2}$ at $37^{\circ} \mathrm{C}$. The papillary muscles from the right ventricle were individually mounted in a tissue chamber (volume $\approx 50 \mathrm{ml}$ ). Each preparation was initially stimulated (HSE [Hugo Sachs Electronik] stimulator type 215/II, March-Hugstetten, Germany) at a basic cycle length of 500 $\mathrm{ms}$ (frequency $=2 \mathrm{~Hz}$ ), using 2-ms long rectangular constant voltage pulses isolated from ground and delivered across bipolar platinum electrodes in contact with the preparation. We applied the following types of stimulation in the course of the experiments: stimulation with a constant cycle length of $500 \mathrm{~ms}(2 \mathrm{~Hz})$; stimulation with different constant cycle lengths ranging from 300 to 5000 ms taking the measurement after the 25 th beat.

To determine the recovery of $V_{\max }$, extra test action potentials were elicited using single test pulses $\left(S_{2}\right)$ in a preparation driven at a basic cycle length of $500 \mathrm{~ms}$. The $\mathrm{S}_{1}-\mathrm{S}_{2}$ coupling interval was increased progressively from the end of the effective refractory period up to $10 \mathrm{~s}$. The time constant for recovery of $V_{\max }$ was fitted to a single exponential function, starting at the $40 \mathrm{~ms}$ diastolic interval and ending at $5 \mathrm{~s}$.

Before the control measurement, at least $1 \mathrm{~h}$ was allowed for each preparation to equilibrate while being continuously superfused with Tyrode's solution. The temperature of the superfusate was kept constant at $37^{\circ} \mathrm{C}$. Transmembrane potentials were recorded using a conven- tional microelectrode technique. Microelectrodes filled with $3 \mathrm{M} \mathrm{KCl}$ and having tip resistances of 5-20 $\mathrm{m} \Omega$ were connected to the input of a high impedance electrometer (HSE microelectrode amplifier type 309), which was referenced to the ground. The first derivative of transmembrane potentials $\left(V_{\max }\right)$ was electronically derived by an HSE differentiator (type 309). The voltage outputs from all amplifiers were displayed on a dual-beam memory oscilloscope (Tektronix $2230100 \mathrm{MHz}$ digital storage oscilloscope, Beaverton, OR).

The maximum diastolic potential (MDP), action potential amplitude (APA), and action potential duration measured at $50 \%$ and $90 \%$ repolarization $\left(\mathrm{APD}_{50-90}\right)$ were obtained using software developed in our department (HSE-APES). GYKI-16638 was dissolved in dimethyl sulfoxide (DMSO) as a 1-mM stock solution. After the control measurements, GYKI-16638 was added to the tissue bath to obtain a final concentration of $2 \mu \mathrm{M}$ and the measurements were repeated after a 30-min incubation time.

To select the single in vitro concentration, we were guided by pharmacokinetic studies with GYKI-16638. In these measurements, the obtained plasma concentration after GYKI-16638 administration correlated well with the concentration used in our in vitro studies with GYKI16638.

\subsection{Whole-cell configuration of the patch-clamp technique}

Single ventricular myocytes were obtained by enzymatic dissociation from New Zealand rabbits (1-2 kg) by a technique described earlier in detail (Varró et al., 1996).

One drop of cell suspension was placed in a transparent recording chamber mounted on the stage of an inverted microscope (TMS; Nikon, Tokyo, Japan), and at least 5 min were allowed for individual myocytes to settle and adhere to the bottom of the chamber before superfusion was started. Myocytes that were used were rod-shaped with clear striations. HEPES-buffered Tyrode solution served as the normal superfusate in all experiments. This solution contained (mM): $\mathrm{NaCl} 144, \mathrm{NaH}_{2} \mathrm{PO}_{4} 0.33, \mathrm{KCl}$ 4.0, $\mathrm{CaCl}_{2}$ 1.8, $\mathrm{MgCl}_{2}$ 0.53, glucose 5.5, and HEPES 5.0 at $\mathrm{pH} 7.4$.

Patch-clamp micropipettes were made from borosilicate glass capillaries (Clark, Reading, UK) using a P-97 Flaming/Brown micropipette puller (Sutter Instrument Co, Novato, CA, USA). These electrodes had resistances between 1.5 and $2.5 \mathrm{M} \Omega$ when filled with pipette solution containing (in mM): K-aspartate $100, \mathrm{KCl} 45, \mathrm{~K}_{2} \mathrm{ATP} 3, \mathrm{MgCl}_{2}$ 1, EGTA 10, and HEPES 5. The $\mathrm{pH}$ of this solution was adjusted to 7.2 by addition of $\mathrm{KOH}$. Nisoldipine ( $1 \mu \mathrm{M}$; Bayer, Leverkusen, Germany) in the external solution eliminated the inward $\mathrm{Ca}^{2+}$ current $\left(I_{\mathrm{Ca}}\right)$. An Axopatch-1D amplifier (Axon Instruments, Foster City, CA, USA) was used to record the membrane current in the whole-cell 
Table 1

Effect of intravenous administration of D-sotalol and GYKI-16638 on mean arterial blood pressure, heart rate, $\mathrm{QT}$ and $\mathrm{QT}_{\mathrm{c}}$ intervals in anaesthetized rabbits

\begin{tabular}{|c|c|c|c|c|c|}
\hline Group & $\begin{array}{l}\text { Dose } \\
(\mathrm{mg} / \mathrm{kg})\end{array}$ & & $n$ & $\begin{array}{l}\text { Before } \\
\text { infusion }\end{array}$ & $\begin{array}{l}5 \text { min after } \\
\text { infusion }\end{array}$ \\
\hline \multirow[t]{4}{*}{ Control } & & MBP & 19 & $101 \pm 2.8$ & $100 \pm 2.6$ \\
\hline & & HR & & $271 \pm 7.2$ & $268 \pm 6.6$ \\
\hline & & QT & & $149 \pm 4.0$ & $149 \pm 4.4$ \\
\hline & & $\mathrm{QT}_{\mathrm{c}}$ & & $162 \pm 3.4$ & $162 \pm 3.8$ \\
\hline \multirow[t]{8}{*}{ D-sotalol } & 1.0 & MBP & 13 & $97 \pm 3.2$ & $97 \pm 2.7$ \\
\hline & & HR & & $272 \pm 9.4$ & $252 \pm 8.9^{\mathrm{a}}$ \\
\hline & & QT & & $142 \pm 4.7$ & $162 \pm 5.2^{\mathrm{a}}$ \\
\hline & & $\mathrm{QT}_{\mathrm{c}}$ & & $156 \pm 3.9$ & $172 \pm 4.0^{\mathrm{a}}$ \\
\hline & 3.0 & MBP & 13 & $95 \pm 3.5$ & $100 \pm 3.3$ \\
\hline & & HR & & $265 \pm 9.7$ & $247 \pm 7.9^{\mathrm{a}}$ \\
\hline & & QT & & $150 \pm 6.8$ & $167 \pm 6.7^{\mathrm{a}}$ \\
\hline & & $\mathrm{QT}_{\mathrm{c}}$ & & $163 \pm 5.9$ & $176 \pm 5.8^{\mathrm{a}}$ \\
\hline \multirow[t]{8}{*}{ GYKI-16638 } & 0.03 & MBP & 14 & $93 \pm 3.4$ & $93 \pm 2.8$ \\
\hline & & HR & & $273 \pm 5.2$ & $259 \pm 6.3^{\mathrm{a}}$ \\
\hline & & QT & & $150 \pm 4.6$ & $159 \pm 7.3$ \\
\hline & & $\mathrm{QT}_{\mathrm{c}}$ & & $164 \pm 4.1$ & $171 \pm 6.5$ \\
\hline & 0.1 & MBP & 17 & $94 \pm 2.7$ & $93 \pm 2.5$ \\
\hline & & HR & & $270 \pm 8.7$ & $253 \pm 7.3^{\mathrm{a}}$ \\
\hline & & QT & & $140 \pm 4.4$ & $166 \pm 6.4^{\mathrm{a}, \mathrm{b}}$ \\
\hline & & $\mathrm{QT}_{\mathrm{c}}$ & & $153 \pm 3.4$ & $173 \pm 4.7^{\mathrm{a}}$ \\
\hline
\end{tabular}

$n=$ Number of animals, $\mathrm{MBP}=$ mean blood pressure $(\mathrm{mm} \mathrm{Hg}), \mathrm{HR}=$ heart rate $(1 / \mathrm{min}), \mathrm{QT}=\mathrm{QT}$ interval $(\mathrm{ms}), \mathrm{QT}_{\mathrm{c}}=\mathrm{QT}_{\mathrm{c}}$ interval.

${ }^{\mathrm{a}} P<0.05$, compared to the preinfusion value of the same group.

${ }^{\mathrm{b}} P<0.05$, compared to the control group.

configuration of the patch-clamp technique. After a high $(1-10 \mathrm{G} \Omega)$ resistance seal was established by gentle suction, the cell membrane beneath the tip of the electrode was disrupted by further suction or by application of $1.5 \mathrm{~V}$ electrical pulses applied for $1-5 \mathrm{~ms}$. Series resistance was typically 4-8 M $\Omega$ prior to compensation (50-80\%, depending on the voltage protocol utilized). Experiments, where the series resistance was high, or where it increased substantially during measurement, were terminated and the data were discarded. Membrane currents were digitized using a 333-kHz analog-to-digital converter (Digidata 1200, Axon Instruments) under software control (pClamp 6.0, Axon Instruments). Analyses were performed using Axon
(pClamp 6.0) software after low-pass filtering at $1 \mathrm{kHz}$. All patch-clamp data were collected at $37^{\circ} \mathrm{C}$.

GYKI-16638 was diluted at the time of use from a $10-\mathrm{mM}$ stock solution containing $100 \%$ DMSO. DMSO at the resulting concentrations $(0.2 \%)$ produced no discernible effect on APD or the membrane currents assessed. All stock solutions were prepared using HEPES-buffered Tyrode solution as the solvent.

\subsection{Statistical evaluation}

For the evaluation of data obtained from the cellular electrophysiology experiments, Student's $t$-test for paired data was used. All data are expressed as means \pm standard error of the mean (S.E.M.).

The incidence of arrhythmias was calculated and compared by using the $\chi^{2}$ method. All other variables are expressed as means \pm S.E.M. and, after analysis of variance, were compared by means of the modified $t$ statistic of Wallenstein et al. (1980). Differences were considered significant when $P$ values were less than 0.05 .

\section{Results}

\subsection{Effect of GYKI-16638 on haemodynamic variables in anaesthetized rabbits}

There were no significant differences between the mean arterial blood pressures of control and D-sotalol- or GYKI16638-treated animals. Mean arterial blood pressure fell significantly in all groups due to coronary artery occlusion as compared to preocclusion values ( $74 \pm 3.9$ vs. $101 \pm 2.8$ $\mathrm{mm} \mathrm{Hg}, 78 \pm 4.5$ vs. $97 \pm 3.2 \mathrm{~mm} \mathrm{Hg}, 84 \pm 2.6$ vs. $95 \pm 3.5 \mathrm{~mm} \mathrm{Hg}, 69 \pm 3.8$ vs. $93 \pm 3.4 \mathrm{~mm} \mathrm{Hg}$ and $74 \pm 3.9$ vs. $94 \pm 2.7 \mathrm{~mm} \mathrm{Hg}$ in controls, 1 and $3 \mathrm{mg} / \mathrm{kg}$ D-sotalol-, 0.03 and $0.1 \mathrm{mg} / \mathrm{kg} \mathrm{GYKI}-16638$-treated animals, respectively, all $P<0.05$ ).

The infusion of 1 and $3 \mathrm{mg} / \mathrm{kg}$ D-sotalol, as well as 0.03 and $0.1 \mathrm{mg} / \mathrm{kg} \mathrm{GYKI}-16638$, significantly decreased the heart rate of rabbits compared to the basal values

Table 2

Effect of D-sotalol and GYKI-16638 on the incidence of arrhythmias during 10 min of coronary artery occlusion in anaesthetized rabbits

\begin{tabular}{|c|c|c|c|c|c|c|}
\hline \multirow[t]{2}{*}{ Group } & \multirow[t]{2}{*}{ Dose $(\mathrm{mg} / \mathrm{kg})$} & \multirow[t]{2}{*}{$n$} & \multicolumn{4}{|c|}{ Incidence of arrhythmias $(N / \%)$} \\
\hline & & & None & $\mathrm{VF}$ & VT & Other \\
\hline Control & & 19 & $4 / 19(21 \%)$ & $8 / 19(42 \%)$ & $2 / 19(11 \%)$ & $14 / 19(74 \%)$ \\
\hline \multirow[t]{2}{*}{ D-Sotalol } & 1.0 & 13 & $5 / 13(38 \%)$ & $1 / 13(8 \%)$ & $0 / 13(0 \%)$ & $8 / 13(62 \%)$ \\
\hline & 3.0 & 13 & $7 / 13(54 \%)$ & $1 / 13(8 \%)$ & $0 / 13(0 \%)$ & $6 / 13(46 \%)$ \\
\hline \multirow[t]{2}{*}{ GYKI-16638 } & 0.03 & 14 & $3 / 14(21 \%)$ & $3 / 14(21 \%)$ & $2 / 14(14 \%)$ & $11 / 14(79 \%)$ \\
\hline & 0.1 & 17 & $5 / 17(29 \%)$ & $4 / 17(24 \%)$ & $0 / 17(0 \%)$ & $12 / 17(71 \%)$ \\
\hline
\end{tabular}

$n=$ Total number of animals; $N=$ number of animals exhibiting the given response; $\%=$ percentage of the animals exhibiting the given response. $\mathrm{VF}=$ ventricular fibrillation; $\mathrm{VT}=$ ventricular tachycardia; Other $=$ extrasystoles, salvos, and /or bigeminy. 
Table 3

Effect of D-sotalol and GYKI-16638 on the incidence of arrhythmias during 10 min of reperfusion following 10 min of coronary occlusion in anaesthetized rabbits

\begin{tabular}{|c|c|c|c|c|c|c|}
\hline \multirow[t]{2}{*}{ Group } & \multirow[t]{2}{*}{ Dose $(\mathrm{mg} / \mathrm{kg})$} & \multirow[t]{2}{*}{$n$} & \multicolumn{4}{|c|}{ Incidence of arrhythmias $(N / \%)$} \\
\hline & & & None & VF & VT & Other \\
\hline Control & & 11 & $0 / 11(0 \%)$ & $9 / 11(82 \%)$ & $7 / 11(64 \%)$ & $5 / 11(46 \%)$ \\
\hline D-Sotalol & 3.0 & 12 & $4 / 12(33 \%)$ & $2 / 12(17 \%)^{\mathrm{a}}$ & $4 / 12(33 \%)$ & $9 / 12(75 \%)$ \\
\hline \multirow{2}{*}{ GYKI-16638 } & 0.03 & 11 & $3 / 11(27 \%)$ & $2 / 11(18 \%)^{\mathrm{a}}$ & $4 / 11(36 \%)$ & $9 / 11(82 \%)$ \\
\hline & 0.1 & 13 & $6 / 13(46 \%)^{\mathrm{a}}$ & $3 / 13(23 \%)^{\mathrm{a}}$ & $6 / 13(46 \%)$ & $8 / 13(62 \%)$ \\
\hline
\end{tabular}

$n=$ Total number of animals; $N=$ number of animals exhibiting the given response; $\%=$ percentage of the animals exhibiting the given response. $\mathrm{VF}=$ ventricular fibrillation; $\mathrm{VT}=$ ventricular tachycardia; Other $=$ extrasystoles, salvos, and /or bigeminy.

${ }^{\mathrm{a}} P<0.05$.

(Table 1). Coronary occlusion did not change heart rate significantly compared to preocclusion values. No significant changes occurred in the heart rate of animals during reperfusion.

\subsection{Effect of GYKI-16638 on $Q T$ and $Q T_{c}$ intervals in anaesthetized rabbits}

D-Sotalol infusion, in the dose of 1 and $3 \mathrm{mg} / \mathrm{kg}$, significantly lengthened QT and $\mathrm{QT}_{\mathrm{c}}$ intervals (Table 1). GYKI-16638, in the dose of $0.03 \mathrm{mg} / \mathrm{kg}$, had no effect on QT and $\mathrm{QT}_{\mathrm{c}}$ intervals, but caused a significant increase of both variables in the dose of $0.1 \mathrm{mg} / \mathrm{kg}$. No significant changes occurred in the $\mathrm{QT}$ or $\mathrm{QT}_{\mathrm{c}}$ intervals during reperfusion.

\subsection{Arrhythmias during 10 min of myocardial ischaemia}

In all groups, arrhythmias did not develop either during the 1-min infusion of drugs or vehicle, or between the infusion of drugs and coronary occlusion.

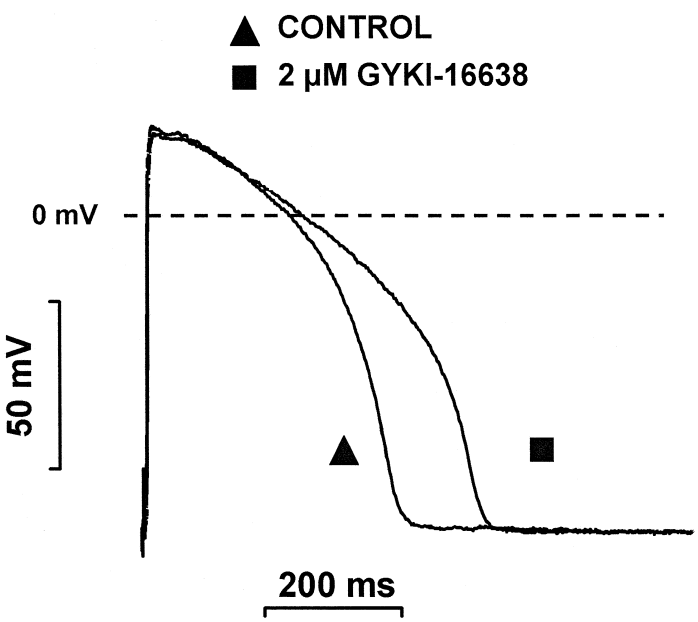

Fig. 2. Effect of $2 \mu \mathrm{M}$ GYKI-16638 on the action potential in rabbit right ventricular papillary muscle (stimulation frequency: $2 \mathrm{~Hz}$ ).
The incidence of arrhythmias in the control, D-sotaloland GYKI-16638-treated groups during $10 \mathrm{~min}$ of coronary artery occlusion is shown in Table 2 . The incidence of ventricular fibrillation was not statistically different in the D-sotalol- or GYKI-16638-treated animals compared to the control group.

There were no significant differences in the treated and control groups with respect to the incidence of other types of arrhythmias during $10 \mathrm{~min}$ of coronary artery ligation.

\subsection{Reperfusion-induced arrhythmias}

Arrhythmias induced by reperfusion appeared within 10-30 s following the release of the coronary artery ligature.

D-Sotalol (1 and $3 \mathrm{mg} / \mathrm{kg}$ ) and $0.03 \mathrm{mg} / \mathrm{kg} \mathrm{GYKI-}$ 16638 pretreatment significantly reduced the incidence of reperfusion-induced ventricular fibrillation (Table 3). All drug pretreatments significantly increased the number of animals surviving reperfusion (75\% and $83 \%$ with 1 and 3 $\mathrm{mg} / \mathrm{kg}$ D-sotalol, $82 \%$ and $77 \%$ with 0.03 and $0.1 \mathrm{mg} / \mathrm{kg}$ GYKI-16638 vs. $18 \%$ in controls, $P<0.05$, respectively).

The number of animals that did not develop any arrhythmia during reperfusion was significantly higher in the

Table 4

The effect of $2 \mu \mathrm{M}$ GYKI-16638 on the action potential parameters in rabbit right ventricular papillary muscle

\begin{tabular}{lcc}
\hline$n=6$ & Control & $2 \mu$ M GYKI-16638 \\
\hline$R P(m V)$ & $-89 \pm 1.5$ & $-91 \pm 0.8$ \\
APA (mV) & $111.7 \pm 2.1$ & $112 \pm 2.8$ \\
$\operatorname{APD}_{50}(\mathrm{~ms})$ & $158.3 \pm 12.4$ & $194.5 \pm 12.7^{\mathrm{a}}$ \\
$\operatorname{APD}_{90}(\mathrm{~ms})$ & $205.8 \pm 15.9$ & $254.8 \pm 14.9^{\mathrm{a}}$ \\
$V_{\max }(\mathrm{V} / \mathrm{s})$ & $208.3 \pm 32.8$ & $169.2 \pm 20.8^{\mathrm{a}}$ \\
\hline
\end{tabular}

$\mathrm{RP}=$ resting potential; $\mathrm{APA}=$ action potential amplitude; $\mathrm{APD}_{50}=50 \%$ repolarization time; $\mathrm{APD}_{90}=90 \%$ repolarization time; $V_{\max }=$ maximum upstroke velocity; stimulation frequency: $2 \mathrm{~Hz}$.

${ }^{\mathrm{a}} P<0.05$. 


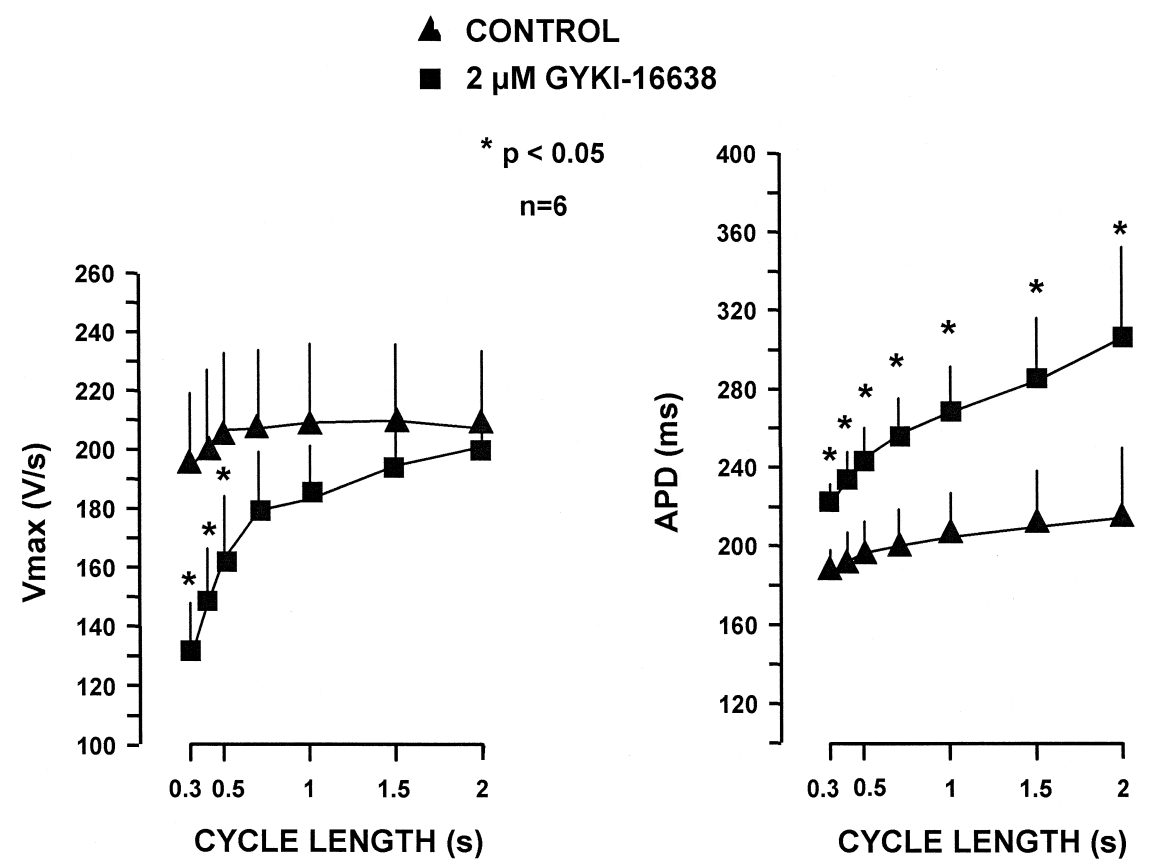

Fig. 3. Frequency-dependent effect of $2 \mu \mathrm{M}$ GYKI-16638 on maximum upstroke velocity $\left(V_{\max }\right)$ and APD in rabbit right ventricular papillary muscle.
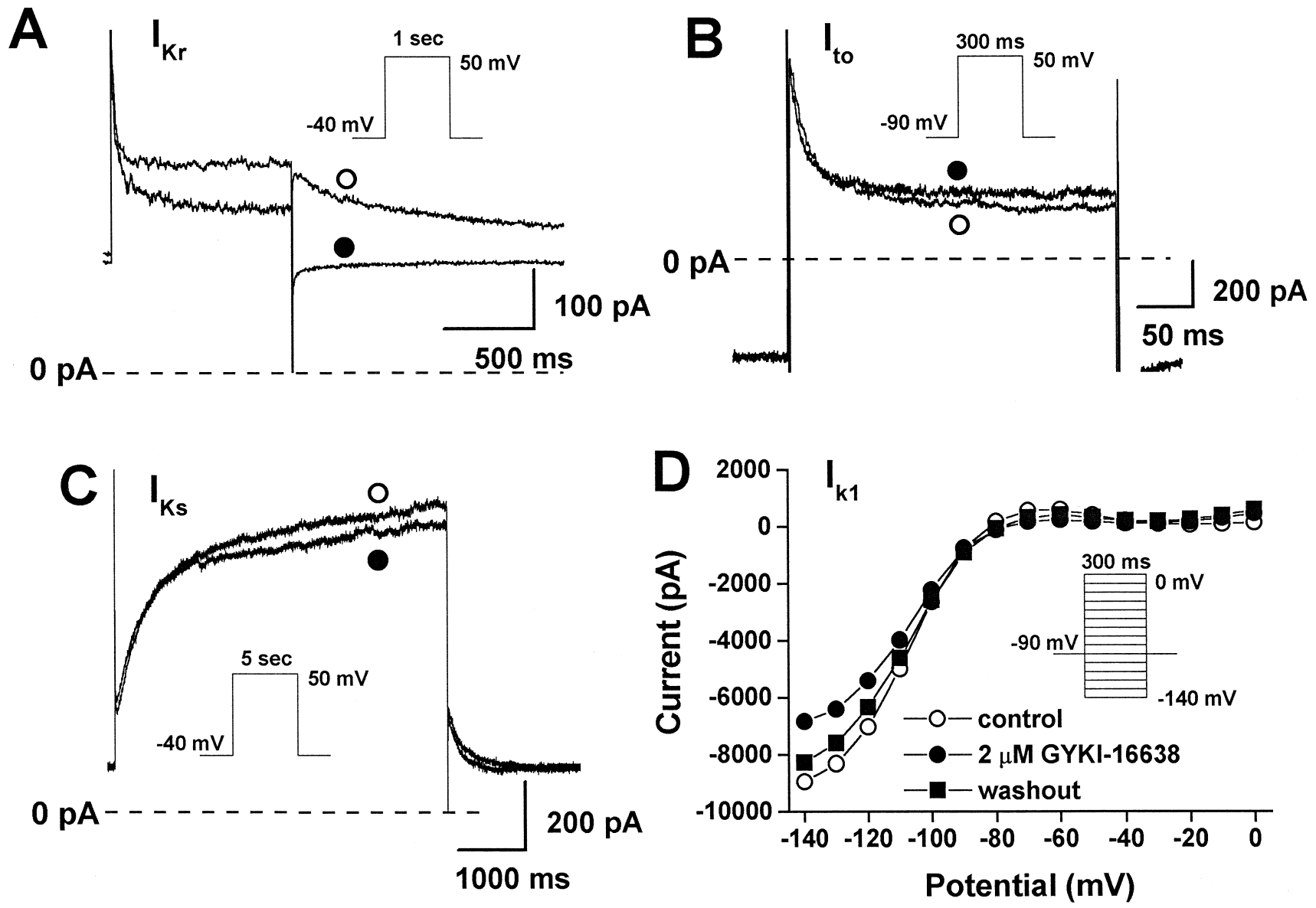

Fig. 4. Effect of $2 \mu \mathrm{M}$ GYKI-16638 (A) on the rapid component of the delayed rectifier outward $\mathrm{K}^{+}$current $\left(I_{\mathrm{Kr}}\right)$, (B) on the transient outward current $\left(I_{\mathrm{to}}\right),(\mathrm{C})$ on the slow component of the delayed rectifier $\mathrm{K}^{+}$current $\left(I_{\mathrm{Ks}}\right)$, and $(\mathrm{D})$ on the inward rectifier potassium current $\left(I_{\mathrm{k} 1}\right)$. Pulse protocols are shown as insets. 
$0.1 \mathrm{mg} / \mathrm{kg}$ GYKI-16638-treated group (Table 3). There were no differences in the incidence of other types of arrhythmias between the animals receiving pretreatment and control rabbits during reperfusion (Table 3).

\subsection{Effect of GYKI-16638 on the action potentials in rabbit papillary muscle}

The effect of $2 \mu \mathrm{M}$ GYKI-16638 on the action potentials at $2 \mathrm{~Hz}$ stimulation frequency in rabbit right ventricular papillary muscle is shown in Fig. 2 and Table 4. At 2 $\mathrm{Hz}$ stimulation frequency, $2 \mu \mathrm{M}$ GYKI-16638 did not significantly influence the resting membrane potential and the APA, but it lengthened repolarization, measured as $\mathrm{APD}_{50}$ and $\mathrm{APD}_{90}$. The maximal rate of depolarization $\left(V_{\max }\right)$ was also significantly reduced. The observed decrease of $V_{\max }$ in the presence of $2 \mu \mathrm{M}$ GYKI-16638 was use-dependent and became significant only at stimulation cycle lengths shorter than $700 \mathrm{~ms}$ (Fig. 3). This was consistent with a delayed recovery of $V_{\max }$ measured in the presence of the drug $(\tau<30 \mathrm{~ms}$ in controls, and $328.2 \pm$ $65.0 \mathrm{~ms},(n=4)$ with $2 \mu \mathrm{M}$ GYKI-16638). The APD prolongation induced by $2 \mu \mathrm{M}$ GYKI-16638 was reverse use-dependent: the slower the stimulation frequency, the more pronounced the APD prolongation (Fig. 3).

\subsection{Effect of GYKI-16638 on various transmembrane $K^{+}$ currents in isolated rabbit ventricular myocytes}

The effect of GYKI-16638 on various $\mathrm{K}^{+}$currents was studied in isolated single rabbit ventricular myocytes (Fig. 4). The rapid component of the delayed rectifier outward $\mathrm{K}^{+}$current $\left(I_{\mathrm{Kr}}\right)$ was elicited from $-40 \mathrm{mV}$ holding potential to various 1 -s long test pulses ranging from -20 to $+50 \mathrm{mV}$ and then returning back to $-40 \mathrm{mV}$. The amplitude of the deactivating tail current at this potential was measured as the difference between the peak tail current and the holding current level and was attributed to $I_{\mathrm{Kr}}($ at $+50 \mathrm{mV}$, it was $86.9 \pm 16.6 \mathrm{pA}, n=4)$. Because of the very slow deactivation of $I_{\mathrm{Kr}}$, the pulsing frequency in these experiments was $0.01 \mathrm{~Hz}$. As Fig. 4A shows, 2 $\mu \mathrm{M}$ GYKI-16638 completely inhibited the $I_{\mathrm{Kr}}$ tail current. Similar results were obtained in three other cells.

Fig. 4B and C shows that $2 \mu \mathrm{M}$ GYKI-16638 did not change or only minimally affected the transient outward $\left(I_{\mathrm{to}}\right)$ and the slow component of the delayed rectifier $\mathrm{K}^{+}$ currents. Similar results were found in three other cells.

The effect of $2 \mathrm{mM}$ GYKI-16638 on the inward rectifier $\mathrm{K}^{+}$current $\left(I_{\mathrm{k} 1}\right)$ was studied at a holding potential of $-80 \mathrm{mV}$ and was elicited by $300-\mathrm{ms}$ long voltage pulses to various potentials ranging from -140 to $0 \mathrm{mV}$. $I_{\mathrm{k} 1}$ was determined as the steady-state current at the end of the voltage pulses. As a result of a representative experiment, Fig. 4D shows that $2 \mathrm{mM}$ GYKI-16638 moderately decreased the amplitude of the steady state current-voltage relationship attributed to inhibition of $I_{\mathrm{k} 1}$. This effect was reversible upon $5 \mathrm{~min}$ of washout. The average value of the $I_{\mathrm{k} 1}$ current $(n=7)$ at $-100 \mathrm{mV}$ before drug superfusion was $-2648 \pm 399 \mathrm{pA}$, which was significantly reduced to $-2152 \pm 401 \mathrm{pA}$ after $5 \mathrm{~min}$ of superfusion with 2 mM GYKI-16638.

\section{Discussion}

The recently developed GYKI-16638 is a member of a new series of $N$-(phenoxyalkyl)- $N$-phenylalkylamine compounds. Its structure combines Class I/B and Class III structural elements, i.e. those of D-sotalol and mexiletine.

In the present study, the antiarrhythmic effect of GYKI16638 in anaesthetized rabbits and its electrophysiological effects in rabbit right ventricular papillary muscle preparations were investigated. We compared the antiarrhythmic effect of GYKI-16638 to that of D-sotalol, a well-known pure Class III antiarrhythmic agent.

GYKI-16638 exerted an antiarrhythmic effect in our experiments that was comparable to that of D-sotalol. Both compounds significantly decreased the number of animals that died due to lethal ventricular arrhythmias during reperfusion after $10 \mathrm{~min}$ of regional myocardial ischaemia. The significant improvement of survival during reperfusion occurred in spite of the fact that there were animals that had reversible ventricular fibrillation in the control group as well. This is a well-known phenomenon in experimental arrhythmia studies, i.e. relatively small hearts can recover from ventricular fibrillation, while in human and large animal hearts, this arrhythmia is irreversible (Botting et al., 1986).

The antiarrhythmic activity of GYKI-16638 was already observed after the administration of the lower dose which did not influence QT and $\mathrm{QT}_{\mathrm{c}}$ intervals. This may suggest that GYKI-16638 has a mechanism of action that is based not solely on the prolongation of repolarization. Indeed, it was found that GYKI-16638 not only caused a significant increase in APD and, consequently, in the effective refractory period, but that it also significantly reduced the maximum upstroke velocity $\left(V_{\max }\right)$ in rabbit right ventricular papillary muscles, reflecting its fast $\mathrm{Na}^{+}$channel $\left(I_{\mathrm{Na}}\right)$ blocking ability. However, it was found that, in a higher dose, it significantly prolonged the QT and $\mathrm{QT}_{\mathrm{c}}$ intervals in anaesthetized rabbits, as was expected from its in vitro effect on the APD. The $\mathrm{Na}^{+}$channel blocking effect was significant only at cycle lengths shorter than $700 \mathrm{~ms}$. This was consistent with the measured time constant for recovery of $V_{\max }$, which resembled that of Class I/B type drugs (Campbell, 1983) and amiodarone (Varró et al., 1985). Such an effect may have therapeutic importance in the inhibition of arrhythmias due to early afterdepolarizations (Papp et al., 1996).

D-Sotalol has been shown to exert an antiarrhythmic effect in a number of animal (Lynch et al., 1985; Usui et 
al., 1993; Hashimoto et al., 1995) and human studies (Hohnloser et al., 1995; Koch et al., 1995) with a proposed mechanism of action of terminating re-entry (Fei and Frame, 1996). However, it was shown in the SWORD trial that D-sotalol increased mortality in patients with myocardial infarction (Waldo et al., 1996). The results shifted attention towards antiarrhythmic compounds with a combined mechanism of action. As an example, amiodarone, an antiarrhythmic agent with a complex mode of action, has attracted a great deal of interest recently. It has been shown to decrease ventricular fibrillation vulnerability in rabbit hearts following long-term pretreatment (Behrens et al., 1997), to be protective against ischaemia- and reperfusion-induced arrhythmias (Varró and Rabloczky, 1986; Coker and Chess-Williams, 1991; Li and Northover, 1992), and to be effective in the treatment of life-threatening ventricular arrhythmias in humans (Singh, 1999). Also, some multicenter clinical trials have shown that amiodarone may reduce the incidence of arrhythmia-related sudden death (Julian et al., 1997; Cairns et al., 1997). Several electrophysiological studies showed that amiodarone possessed both Class I/B and Class III antiarrhythmic properties (Singh and Vaughan Williams, 1970; Varró et al., 1985; Honjo et al., 1991; Maruyama et al., 1995), as well as $\mathrm{Ca}^{2+}$ channel blocking (Nattel et al., 1987) and sympatholytic effects (Polster and Broekhuysen, 1976). While effectively diminishing the development of re-entry arrhythmias, selective $I_{\mathrm{Kr}}$ blockers can increase the incidence of arrhythmias, by increasing the interventricular dispersion of repolarization and initiating early afterdepolarizations, leading to torsade de pointes tachycardia (Verduyn et al., 1997; Hohnloser, 1997). It was demonstrated that almokalant, a selective $I_{\mathrm{Kr}}$ blocker, significantly reduced the incidence of coronary artery occlusion / reperfusion-induced arrhythmias but also showed marked proarrhythmic activity (Carlsson et al., 1993a; Farkas et al., 1998). D-Sotalol has also been shown to induce torsades de pointes in animals (Buchanan et al., 1993; Vos et al., 1995) and humans (Gottlieb et al., 1997).

Amiodarone was found to have a remarkably low potential for inducing torsades de pointes tachyarrhythmias despite its ability to prolong the $\mathrm{QT}_{\mathrm{c}}$ interval (Hohnloser et al., 1994). The decrease in the transmural dispersion of ventricular repolarization and the consequent inhibition of the development of early afterdepolarization can possibly explain this effect of amiodarone (Sicouri et al., 1997). Class I/B antiarrhythmics may reduce the occurrence of this arrhythmia. Mexiletine (Shimizu and Antzelevitch, 1997) and lidocaine in both animal (Carlsson et al., 1993b) and human studies (Assimes and Malcolm, 1998) were shown to suppress torsades de pointes induced by D-sotalol. Antiarrhythmic drugs with a Class I/B action have also been shown to be effective against coronary artery occlusion/reperfusion-induced arrhythmias (Bonaduce et al., 1986; Uematsu et al., 1986; He et al., 1992; Komori et al., 1995). Also, the combination of mexiletine and sotalol prevented ventricular tachycardia induced by programmed stimulation in dogs with chronic infarction (Chezalviel et al., 1993), and Luderitz et al. (1991) concluded in their review that in humans, the combination of mexiletine and sotalol suppressed both premature ventricular beats and complex ventricular arrhythmias more effectively than sotalol alone. These results suggest that an antiarrhythmic compound with combined Class III and Class I/B effects could reduce the incidence of re-entry arrhythmias without a high risk of inducing torsades de pointes arrhythmias.

The exact ionic mechanism of the electrophysiologic and antiarrhythmic effects of GYKI-16638 is not fully understood. As mentioned above, the use-dependent depression of $V_{\max }$ strongly argues for inhibition of the fast inward $\mathrm{Na}^{+}$current. The APD lengthening effect of the compound can be best explained by the marked depression of $I_{\mathrm{Kr}}$ and, to a lesser extent, by the decrease of the $I_{\mathrm{k} 1}$. Therefore, based on the cellular electrophysiological measurements, GYKI-16638 can be regarded as an antiarrhythmic compound which — like amiodarone (Varró et al., 1996; Kodama et al., 1997) — interferes with multiple transmembrane ion channels.

When administered chronically, amiodarone exhibits serious extracardiac side effects that limit its use (Hilleman et al., 1998). GYKI-16638 shares some (Class I/B + Class III), but not all of the electrophysiological properties of amiodarone and its chemical structure is also different. Based on its different chemical structure, it can be reasonably expected that this compound, unlike amiodarone, will be relatively free of extracardiac side effects. Due to its Class I/B action, it is also expected that the compound will lack the significant inhibitory effect on conduction at a normal heart rate. The compound also showed reverse frequency-dependent prolongation of APD in rabbit papillary muscle (Fig. 3), an effect which resembles that of D-sotalol or any specific $I_{\mathrm{Kr}}$ blocker. Therefore, further studies are needed to elucidate the possible side effects of GYKI-16638, including its capability to induce torsades de pointes or conduction disturbance-related arrhythmias.

The haemodynamic side effects of antiarrhythmic agents are of particular importance. GYKI-16638 did not change the mean arterial blood pressure, but decreased the heart rate of anaesthetized rabbits. We also found that the administration of D-sotalol significantly decreased heart rate in rabbits. A similar heart rate decreasing effect of D-sotalol has been shown by Schwartz et al. (1987), although this compound lacks the antiadrenergic properties of D,L-sotalol. A moderate decrease in heart rate may be beneficial, especially in the setting of myocardial ischaemia and reperfusion-induced arrhythmias (Bernier et al., 1989).

In conclusion, we demonstrated that GYKI-16638, a novel antiarrhythmic drug candidate, protected against coronary artery occlusion and reperfusion-induced arrhythmias in anaesthetized rabbits. This protection was already noticed at a lower dose, which did not lengthen the $\mathrm{QT}_{\mathrm{c}}$ interval significantly. Based on the results of our cellular 
electrophysiological investigations in rabbit right ventricular papillary muscle, it can be assumed that GYKI-16638 exerts its antiarrhythmic effect through combined Class I/B and Class III actions.

\section{Acknowledgements}

The technical assistance of Mrs. Zsuzsa Abraham is gratefully acknowledged. The work was supported by the Grants of the Hungarian Ministry of Education (FKFP) No. 1025-1997, National Committee for Technological Development (OMFB) No. 1025, National Research Foundation (OTKA) No. T 032558, T 31910 and T 022300, Hungarian Ministry of Health (ETT) No. 0627 and 600128.

\section{References}

Assimes, T.L., Malcolm, I., 1998. Torsade de pointes with sotalol overdose treated successfully with lidocaine. Can. J. Cardiol. 14, 753-756.

Behrens, S., Li, C., Franz, M.R., 1997. Effects of long-term amiodarone treatment on ventricular-fibrillation vulnerability and defibrillation efficacy in response to monophasic and biphasic shocks. J. Cardiovasc. Pharmacol. 30 (4), 412-418.

Bernier, M., Curtis, M.J., Hearse, D.J., 1989. Ischaemia-induced and reperfusion-induced arrhythmias: importance of heart rate. Am. J. Physiol. 235, 21-31.

Bonaduce, D., Ferrara, N., Abete, P., Longobardi, G., Leosco, D., Canonico, V., Morgano, G., Rengo, F., 1986. Effect of mexiletine on reperfusion-induced ventricular arrhythmias: comparison with lidocaine. Arch. Int. Pharmacodyn. Ther. 284, 19-29.

Botting, J.H., Curtis, M.J., Walker, M.J.A., 1986. Arrhythmias associated with myocardial ischaemia and infarction. Mol. Aspects Med. 8, 307-422.

Buchanan, L.V., Kabell, G., Brunden, M.N., Gibson, J.K., 1993. Comparative assessment of ibutilide, D-sotalol, clofilium, E-4031, and UK68,798 in a rabbit model of proarrhythmia. J. Cardiovasc. Pharmacol. $22,540-549$.

Cairns, J.A., Connolly, S.J., Roberts, R., Gent, M., 1997. Randomised trial of outcome after myocardial infarction in patients with frequent or repetitive ventricular premature depolarisations: CAMIAT. Canadian amiodarone myocardial infarction arrhythmia trial investigators. Lancet 349, 675-682.

Campbell, T.J., 1983. Kinetics of onset of rate-dependent effects of Class I antiarrhythmic drugs are important in determining their effects on refractoriness in guinea-pig ventricle, and provide a theoretical basis for their subclassification. Cardiovasc. Res. 17, 344-352.

Carlsson, L., Abrahamsson, C., Andersson, B., Duker, G., Schiller-Linhardt, G., 1993a. Proarrhythmic effects of the class III agent almokalant: importance of infusion rate, QT dispersion, and early afterdepolarisations. Cardiovasc. Res. 27, 2186-2193.

Carlsson, L., Drews, L., Duker, G., Schiller-Linhardt, G., 1993b. Attenuation of proarrhythmias related to delayed repolarization by low-dose lidocaine in the anesthetized rabbit. J. Pharmacol. Exp. Ther. 267, $1076-1080$

Chezalviel, F., Weissenburger, J., Guhennec, C., Jagueux, M., Davy, J.M., Vernhet, L., Simandoux, V., Poirier, J.M., Cheymol, G., 1993. Antiarrhythmic effect of a sotalol-mexiletine combination on induced ventricular tachycardia in dogs. J. Cardiovasc. Pharmacol. 21 (2), 212-220.
Coker, S.J., 1989. Anesthetized rabbit as a model for ischemia- and reperfusion-induced arrhythmias: effects of quinidine and bretylium. J. Pharmacol. Methods 21, 263-279.

Coker, S.J., Chess-Williams, R., 1991. Amiodarone, adrenoceptor responsiveness and ischaemia- and reperfusion-induced arrhythmias. Eur. J. Pharmacol. 201, 103-109.

Farkas, A., Leprán, I., Papp, J.Gy., 1998. Comparison of the antiarrhythmic and the proarrhythmic effect of almokalant in anaesthetised rabbits. Eur. J. Pharmacol. 346, 245-253.

Fei, H., Frame, L.H., 1996. D-Sotalol terminates reentry by two mechanisms with different dependence on the duration of the excitable gap. J. Pharmacol. Exp. Ther. 277, 174-185.

Gottlieb, S.S., Cines, M., Marshall, J., 1997. Torsades de pointes with administration of high-dose intravenous D-sotalol to a patient with congestive heart failure. Pharmacotherapy 17, 830-831.

Hashimoto, K., Haruno, A., Hirasawa, A., Awaji, T., Xue, Y., Wu, Z., 1995. Effects of the new class III antiarrhythmic drug MS-551 and D-sotalol on canine coronary ligation-reperfusion ventricular arrhythmias. Jpn. J. Pharmacol. 68, 1-9.

He, Z.S., Komori, S., Tamura, K., Hashimoto, K., 1992. Inhibitory effect of moricizine on reperfusion induced tachyarrhythmias in rats - a comparison study with disopyramide and mexiletine. Jpn. Circ. J. 56, $861-865$.

Hilleman, D., Miller, M.A., Parker, R., Doering, P., Pieper, J.A., 1998. Optimal management of amiodarone therapy: efficacy and side effects. Pharmacotherapy 18, 138S-145S.

Hohnloser, S.H., 1997. Proarrhythmia with class III antiarrhythmic drugs: types, risks, and management. Am. J. Cardiol. 80, 82G-89G.

Hohnloser, S.H., Klingenheben, T., Singh, B.N., 1994. Amiodarone-associated proarrhythmic effects. A review with special reference to torsade de pointes tachycardia. Ann. Intern. Med. 121 (7), 529-535.

Hohnloser, S.H., Meinertz, T., Stubbs, P., Crijns, H.J., Blanc, J.J., Rizzon, P., Cheuvart, B., 1995. Efficacy and safety of D-sotalol, a pure class III antiarrhythmic compound, in patients with symptomatic complex ventricular ectopy. Results of a multicenter, randomized, double-blind, placebo-controlled dose-finding study. The D-sotalol PVC Study Group. Circulation 92, 1517-1525.

Honjo, H., Kodama, I., Kamiya, K., Toyama, J., 1991. Block of cardiac $\mathrm{Na}+$ channels by amiodarone studied by using $V_{\max }$ of action potential in single ventricular myocytes. Br. J. Pharmacol. 102, 651-656.

Julian, D.G., Camm, A.J., Frangin, G., Janse, M.J., Munoz, A., Schwartz, P.J., Simon, P., 1997. Randomised trial of effect of amiodarone on mortality in patients with left-ventricular dysfunction after recent myocardial infarction: EMIAT. European Myocardial Infarct Amiodarone Trial Investigators. Lancet 349, 667-674.

Koch, K.T., Duren, D.R., van Zwieten, P.A., 1995. Long-term antiarrhythmic efficacy and safety of D-sotalol in patients with ventricular tachycardia and a low ejection fraction. Cardiovasc. Drugs Ther. 9, 437-443.

Kodama, I., Kamiya, K., Toyama, J., 1997. Cellular electropharmacology of amiodarone. Cardiovasc. Res. 35, 13-29.

Komori, S., Sano, S., Li, B.H., Matsumura, K., Naitoh, A., Mochizuki, S., Ishihara, T., Watanabe, A., Umetani, K., Ijiri, H. et al., 1995. Effects of bidisomide (SC-40230), a new class I antiarrhythmic agent, on ventricular arrhythmias induced by coronary artery occlusion and reperfusion in anaesthetized rats; comparison with mexiletine and disopyramide. Heart Vessels 10, 7-11.

Leprán, I., Koltai, M., Siegmund, W., Szekeres, L., 1983. Coronary artery ligation, early arrhythmias and determination of the ischaemic area in conscious rats. J. Pharmacol. Methods 9, 219-230.

Li, J.Y., Northover, B.J., 1992. Antiarrhythmic and electrophysiological effects of amiodarone, lignocaine, and penticainide in anaesthetised rats. Cardiovasc. Res. 26, 1116-1120.

Luderitz, B., Mletzko, R., Jung, W., Manz, M., 1991. Combination of antiarrhythmic drugs. J. Cardiovasc. Pharmacol. 17 (Suppl. 6), S48S52. 
Lynch, J.J., Coskey, L.A., Montgomery, D.G., Lucchesi, B.R., 1985. Prevention of ventricular fibrillation by dextrorotatory sotalol in a conscious canine model of sudden coronary death. Am. Heart J. 109, 949-958.

Maruyama, T., Richardson, L.C., Sun, W., McCarthy, J.J., Gettes, L.S., 1995. Acute effects of amiodarone on membrane properties, refractoriness, and conduction in guinea pig papillary muscles. Heart Vessels $10,78-86$.

Mason, J.W., 1993. A comparison of seven antiarrhythmic drugs in patients with ventricular tachyarrhythmias. N. Engl. J. Med. 329, 453-458, for the ESVEM Investigators.

Nattel, S., Talajic, M., Quantz, M., DeRoode, M., 1987. Frequency-dependent effects of amiodarone on atrioventricular nodal function and slow-channel action potentials: evidence for $\mathrm{Ca} 2+$ channel-blocking activity. Circulation 76 (2), 442-449.

Papp, J.Gy., Németh, M., Krassói, I., Mester, L., Hála, O., Varró, A., 1996. Differential electrophysiologic effects of chronically administered amiodarone on canine Purkinje fibers versus ventricular muscle. J. Cardiovasc. Pharmacol. Ther. 1 (4), 287-296.

Polster, P., Broekhuysen, J., 1976. The adrenergic antagonism of amiodarone. Biochem. Pharmacol. 25, 131-134.

Schwartz, J., Crocker, K., Wynn, J., Somberg, J.C., 1987. The antiarrhythmic effects of D-sotalol. Am. Heart J. 114, 539-544.

Shimizu, W., Antzelevitch, C., 1997. Na + channel block with mexiletine is effective in reducing dispersion of repolarization and preventing torsade des pointes in LQT2 and LQT3 models of the long-QT syndrome. Circulation 96, 2038-2047.

Sicouri, S., Moro, S., Litovsky, S., Elizari, M.V., Antzelevitch, C., 1997. Chronic amiodarone reduces transmural dispersion of repolarization in the canine heart. J. Cardiovasc. Electrophysiol. 8 (11), 1269-1279.

Singh, B.N., 1999. Current antiarrhythmic drugs: an overview of mechanisms of action and potential clinical utility. J. Cardiovasc. Electrophysiol. 10, 283-301.

Singh, B.N., Vaughan Williams, E.M., 1970. The effect of amiodarone, a new anti-anginal drug, on cardiac muscle. Br. J. Pharmacol. 39 (4), $657-667$

The Cardiac Arrhythmia Suppression Trial (CAST) Investigators, 1989. Preliminary report: effect of encainide and flecainide on mortality in a randomized trial of arrhythmia suppression after after myocardial infarction. N. Engl. J. Med. 321, 406-412.

The Cardiac Arrhythmia Suppression Trial II Investigators, 1992. Effect of the antiarrhythmic agent moricizine on survival after myocardial infarction. N. Engl. J. Med. 327, 227-233.
The CASCADE Investigators, 1993. Randomized antiarrhythmic drug therapy in survivors of cardiac arrest (The CASCADE Study). Am. J. Cardiol. 72, 280-287.

Uematsu, T., Vozeh, S., Ha, H.R., Hof, R.P., Follath, F., 1986. Coronary ligation-reperfusion arrhythmia models in anaesthetized rats and isolated perfused rat hearts. Concentration-effect relationships of lidocaine. J. Pharmacol. Methods 16, 53-61.

Usui, M., Inoue, H., Saihara, S., Sugimoto, T., 1993. Antifibrillatory effects of class III antiarrhythmic drugs: comparative study with flecainide. J. Cardiovasc. Pharmacol. 21, 376-383.

Varró, A., Rabloczky, G., 1986. Antiarrhythmic effect of acute and chronic amiodarone treatment in conscious rats. J. Pharm. Pharmacol. 38 (10), 772-773.

Varró, A., Nakaya, Y., Elharrar, V., Surawicz, B., 1985. Use-dependent effects of amiodarone on $V_{\max }$ in cardiac Purkinje and ventricular muscle fibers. Eur. J. Pharmacol. 112 (3), 419-422.

Varró, A., Virág, L., Papp, J.Gy., 1996. Comparison of the chronic and acute effects of amiodarone on the calcium and potassium currents in rabbit isolated cardiac myocytes. Br. J. Pharmacol. 117, 1181-1186.

Verduyn, S.C., Vos, M.A., van der Zande, J., Kulcsar, A., Wellens, H.J., 1997. Further observations to elucidate the role of interventricular dispersion of repolarization and early afterdepolarizations in the genesis of acquired torsade de pointes arrhythmias: a comparison between almokalant and D-sotalol using the dog as its own control. J. Am. Coll. Cardiol. 30, 1575-1584.

Vos, M.A., Verduyn, S.C., Gorgels, A.P., Lipcsei, G.C., Wellens, H.J., 1995. Reproducible induction of early afterdepolarizations and torsade de pointes arrhythmias by D-sotalol and pacing in dogs with chronic atrioventricular block. Circulation 91, 864-872.

Waldo, A.L., Camm, A.J., deRuyter, H., Friedman, P.L., MacNeil, D.J., Pauls, J.F., Pitt, B., Pratt, C.M., Schwartz, P.J., Veltri, E.P., 1996. Effect of D-sotalol on mortality in patients with left ventricular dysfunction after recent and remote myocardial infarction. The SWORD investigators. Survival with oral D-sotalol. Lancet 348 (9019), $7-12$.

Walker, M.J.A., Curtis, M.J., Hearse, D.J., Campbell, R.W.F., Janse, M.J., Yellon, D.M., Cobbe, S.M., Coker, S.J., Harness, J.B., Harron, D.W.G. et al., 1988. The Lambeth Conventions: guidelines for the study of arrhythmias in ischaemia, infarction and reperfusion. Cardiovasc. Res. 22, 447-455.

Wallenstein, S., Zucher, C.L., Fleiss, J.L., 1980. Some statistical methods useful in circulation research. Circ. Res. 47, 1-9. 